\title{
EXTRACELLULAR AND INTRACELLULAR SYNTHESIS OF SILVER NANOPARTICLES
}

\author{
PRASANNA SUBRAMANIAN*, KIRUBANANDAN SHANMUGAM
}

Former Graduate Student, Centre for Biotechnology, Anna University, Chennai, Tamil Nadu, India. Email: prasanarengarajan@gmail.com

Received: 06 June 2016, Revised and Accepted: 10 June 2016

\section{ABSTRACT}

Objective: The cellular synthesis of nanoparticle is a green process and alternative for a conventional process for the preparation of silver nanoparticles. In our research, focus has been given to the development of an efficient and eco-friendly viable process for the synthesis of silver nanoparticles using cancer and non-cancerous cells, a cell culture that was isolated. The results of this investigation are observed that silver nanoparticles could be induced to synthesis intra- and extra-cellularly using mammalian cells such as cancerous and non-cancerous cells.

Methods: The silver nanoparticles are synthesized by the cancer and non-cancerous cells such as HeLa (Homo sapiens, human), SiHa, and human embryonic kidney-293 cell lines. The silver nanoparticles were characterized by ultraviolet (UV)-visible spectroscopy, transmission electron microscopy (TEM), and X-ray powder diffraction (XRD).

Results: The silver nanoparticles exhibited maximum absorbance at $415 \mathrm{~nm}$ in UV-visible spectroscopy. The XRD confirms the characteristic of the crystal lattice of silver nanoparticles by observing three peaks: Peak at 38 is due to reflection from (111), peak at 44 is due to reflection from (200), and peak at 65 is due to reflection from (220). TEM images showed the formation of stable silver nanoparticles in the cell lines.

Conclusion: The method of extraction of intracellular/extracellular synthesis of silver nanoparticles was inexpensive, simple, and effective in large scale with no need to use of complex process equipment. The cancer cell considered as a biological factory at nanoscale dimension which continued to grow after synthesis of silver nanoparticles. The silver reduction by these cancer cells has occurred through energy-dependent processes that lead to the high output of this reaction. Hence, this new approach of using a mammalian cell for the successful synthesis of nanosized silvers could be easily scaled up, which establishes its commercial viability and also useful in the drug delivery and drug targeting.

Keywords: Silver nanoparticles, Cancer cells, Biosynthesis and characteristics of silver nanoparticles.

(C) 2016 The Authors. Published by Innovare Academic Sciences Pvt Ltd. This is an open access article under the CC BY license (http://creativecommons. org/licenses/by/4. 0/) DOI: http://dx.doi.org/10.22159/ajpcr.2016.v9s2.13302

\section{INTRODUCTION}

The application of nanotechnology in life sciences, called as nanobiotechnology, is already having an impact on diagnostics and drug delivery/targeting. Now, researchers use nanotechnology in the field of drug discovery. Some of these are already established in research through well-known technologies such as biosensors and biochips. "Nanoparticles are still used extensively for developing diagnostics and some of the assays for drug discovery." Nanoscale assays can contribute significantly to cost saving in screening campaigns. "In addition, some nanosubstances could be potential drugs for the future. Although there might be some safety concerns with respect to the in vivo use of nanoparticles, studies are in place to determine the nature and extent of adverse effects. Future prospects for the application of nanotechnology in healthcare and for the development of personalized medicine appear to be excellent." For example, nanoparticulate technology could prove to be very useful in cancer therapy allowing for effective and targeted drug delivery by overcoming the many biological, biophysical, and biomedical barriers that the body stages against a standard intervention such as the administration of drugs or contrast agents. Among nanoparticles, in the biological sciences, many applications for metal nanoparticles are being explored, including biosensors [1], labels for cells and biomolecules [2], and cancer therapeutics [3].

Although a variety of chemical routes have been followed to synthesis of nanoparticles, natural routes are always desired. It has been known for a long time that in nature, a variety of nanomaterials are synthesized by biological processes. "For example, the magnetotactic bacteria synthesize intracellular magnetite or granitite nanocrystallites [4]. Similarly, certain yeasts synthesize intracellular CdS Nanocrystallites through a mechanism of detoxification when growing in the presence of toxic metals such as cadmium [5]." Bacteria involved in silver leaching have been reported to accumulate silver sulfide within their membrane [6], and natural biofilms of sulfate-reducing bacteria were shown to deposit nanocrystalline sphalerite, i.e., ZnS [7]. Owing to the reported particle size uniformity in such "biosynthetic" processes and their inherent environment-friendly nature, there is a renewed interest in biological routes of nanoparticle synthesis [8-10]. "The interest also extends to the assembly of nanoparticles, using biological templates such as DNA or proteins" [1].

It was revealed that in the case of noble-metal nanocrystals, the electromagnetic, optical, and catalytic properties are highly influenced by shape and size [11-13]. Among noble-metal nanomaterials, silver nanoparticles have received considerable attention due to their attractive physicochemical properties. "The surface Plasmon resonance and large effective scattering cross section of individual silver nanoparticles make them ideal candidates for molecular labeling [14] where phenomena such as surface-enhanced Raman scattering can be exploited. In addition, the strong toxicity that silver exhibits in various chemical forms to a wide range of microorganisms is very well known [15-17], and silver nanoparticles have recently been shown to be a promising antimicrobial material [18]. It was found that silver nanoparticles inhibit the virus from binding to host cells as revealed in vitro [19]."

Different approaches of synthesis of silver nanoparticles have been carried out previously [20-22]. Silver nanoparticles were synthesized biologically using fungus and other microorganisms [23,24]. Silver nanoparticles with different sizes were synthesized by electrochemical reduction [25]. Biologically synthesized silver nanoparticles could have many applications, such as spectrally selective coatings for solar energy absorption and intercalation material for electrical batteries [9], optical receptors [14], catalysts in chemical reactions, and bio-labeling [26]. In line with this trend, we have done a novel work in synthesizing silver nanoparticle using human cells. The cells chosen were cancerous and 
non-cancerous cell lines. These synthesized silver nanoparticles have potential application in drug discovery and drug delivery/targeting.

\section{EXPERIMENTAL DETAILS}

\section{Preparation of silver nitrate solution}

Silver ion was prepared in the concentration of $10^{-3} \mathrm{M}$. The solution was prepared in HEPES $(21 \mathrm{mM})$ buffer. Sodium nitrate $(137 \mathrm{mM})$ and sodium hydroxide were added to adjust the $\mathrm{pH}$ to physiological $\mathrm{pH}$.

\section{Preparation of cell culture}

The cultures are viewed to assess the degree of confluency, and the absence of bacterial and fungal contaminants is confirmed. The spent medium is removed. The cell monolayer is washed with HEPES using a volume equivalent to half the volume of culture medium. The wash step if the cells are known to adhere strongly is repeated. The trypsin/ ethylenediaminetetraacetic acid onto the washed cell monolayer using $1 \mathrm{ml}$ per $25 \mathrm{~cm}^{2}$ of surface area is pipetted. The flask is rotated to cover the monolayer with trypsin. The excess trypsin is removed by decantation. The flask is returned to the incubator and left for 2-10 minutes. The cells are examined by an inverted microscope to ensure that all the cells are detached and floating. The side of the flasks may be gently tapped to release any remaining attached cell. The cells are resuspended in a small volume of fresh medium containing medium $(1 \mathrm{ml}$ of $10 \%$ serum containing Dulbecco's Modified Eagles Medium [DMEM]) to inactivate the trypsin. The solution is centrifuged at $3000 \mathrm{rpm}$ for 5 minutes. The cells are resuspended in $1 \mathrm{ml}$ of $10 \%$ serum containing DMEM. The cells are resuspended in $1 \mathrm{ml}$ of $10 \%$ [10]. The cell count is performed (the wells are seeded with same initial value of $3 \times 10^{5}$ cells per well for each kind of cell line). The required number of cells is transferred to a new labeled flask containing pre-warmed medium. It is incubated in $37^{\circ} \mathrm{C}$ $5 \% \mathrm{CO}_{2}$ environment for duration of $48 \mathrm{hrs}$ before ionic solution can be added.

\section{Addition of silver ion solution to cell lines}

Three cell lines (cancerous as well as non-cancerous) were grown to $70 \%$ confluency level after seeding in a 6-well plate $\left(9 \mathrm{~cm}^{2}\right.$, tetraphenylporphyrin with oxygen). The cell lines, which we have used for the study, are human embryonic kidney cell (HEK-293), HeLa cell, and SiHa Cell. During the growth period, culture medium containing DMEM is used. Just before the addition of silver ions to the well, the culture medium is removed. The cells were washed twice with HEPES. Then, silver ion solution in HEPES is filter sterilized using MILLEX ${ }^{\odot} \mathrm{GV}$ Durapore ${ }^{\odot}$ PVDF Membrane filter (pore size: $0.22 \mu \mathrm{m}$ ) and is added to the well. To each well, $2 \mathrm{ml}$ of the solution is added. The cells are then kept in a $37^{\circ} \mathrm{C}, 5 \% \mathrm{CO}_{2}$ incubator. The biotransformation was observed by periodic sampling of aliquots $(200 \mu$ ldiluted to $1 \mathrm{ml}$ of the aqueous component and measuring the ultraviolet (UV)-visible spectrum of the solution. The absorbance values are compared over a period of 4-day. On the last day, the cells are scrapped off the well surface and sample preparation is done for transmission electron microscopy (TEM).

\section{Sample preparation for TEM}

The $\mathrm{Ag}^{2+}$ HEPES solution is removed from well-containing cells. It is washed with HEPES and discards this HEPES (repeat twice). Trypsin $(2 \mathrm{ml})$ is added to the well. The cells are incubated for 5 minutes and $37^{\circ} \mathrm{C}$ and $5 \% \mathrm{CO}_{2}$. The medium is added with serum $(2 \mathrm{ml})$ to the cells. The liquid from well is transferred to a centrifuge tube and carry out centrifugation for 5 minutes at $3000 \mathrm{rpm}$. The pellet is collected after centrifugation. The pellet is resuspended in HEPES. It is centrifuged again under same conditions. The pellet is collected and washed with HEPES twice. This final pellet is collected and resuspended it in 1\% glutaraldehyde. It is stored at $4^{\circ} \mathrm{C}$.

\section{Protocol for cell lysis}

The solution is aspirated. The cells are scarped from the surface of the well using a cell scraper. The solution contained in the well is transferred into a centrifuge tube. The cells are sonicated at duty cycle value of $50 \%$ and in output mode and 3 pulses are given for 10 seconds, each pulse separated by 20 seconds of cooling in ice. It is carried out centrifugation at $5000 \mathrm{rpm}$ for 5 minutes at $4^{\circ} \mathrm{C}$

\section{Ultra-microtome and TEM \\ Fixation}

Primary fixation was done with $1 \%$ glutaraldehyde (as described above). After primary fixation, the cells were washed repeatedly with phosphate buffer and were subjected to secondary fixation with $1 \%$ osmium tetroxide for $1 \mathrm{hr}$ followed by repeated washing with phosphate buffer.

\section{Dehydration}

Before proceeding for dehydration, the cells were suspended in molten agar (2\%). Small blocks of solidified agar $\left(1 \mathrm{~mm}^{2}\right)$ were cut and passed through series of $30 \%, 50 \%$, and $100 \%$ ethanol v/v for 15 minutes each. The lower grade ethanol was prepared in DD water.

\section{Embedding}

The dehydrated agar blocks were suspended in propylene oxide for 20 minutes at $4^{\circ} \mathrm{C}$ ( 2 changes), followed by treatment with $1: 1$ mixture of propylene oxide and Araldite A for $1 \mathrm{hr}$ at $60^{\circ} \mathrm{C}$.

Araldite A: Araldite (resin) Cy-212: $10 \mathrm{ml}$

Dodecenyl succinic anhydride (hardener): $12 \mathrm{ml}$

Dibutyl-phthalate (plasticizer): $1 \mathrm{ml}$

The agar blocks containing cells were then incubated in Araldite A for $1 \mathrm{~h}$ at $60^{\circ} \mathrm{C}$ followed by overnight incubation at room temperature. The next day Araldite B was prepared freshly as follows:

- Araldite A: $23 \mathrm{ml}$

- Trimethyl aminomethyl phenol: $0.4 \mathrm{ml}$ (DMP-30 accelerator)

- Araldite A was poured out and freshly prepared Araldite B was added to the agar blocks. This was followed by incubation for $2 \mathrm{hrs}$ at $60^{\circ} \mathrm{C}$ for infiltration. The blocks were then finally removed and placed in refined beam capsule containing Araldite B and incubated for polymerization for $48-72 \mathrm{hrs}$, at $60^{\circ} \mathrm{C}$.

\section{Block trimming and sectioning}

The resin blocks were carefully trimmed to expose the underlying agar blocks. Sections of various thicknesses $(200 \mathrm{~nm}, 300 \mathrm{~nm}, 500 \mathrm{~nm}$, and $1000 \mathrm{~nm}$ ) were cut using Leica Ultra cut UCT microtome and transferred to 300 mesh copper grids.

\section{Uranyl acetate staining}

$10 \%$ alcoholic solution of uranyl acetate was prepared and centrifuged to remove any precipitate there in. The sections on copper grids were stained for $1 \mathrm{hr}$ with uranyl acetate in dark at room temperature and then washed with distilled water thoroughly.

\section{TEM}

Sections on grids were observed with a TEM working at $120 \mathrm{keV}$.

\section{Instruments used}

The optical spectroscopic studies were done on a Perkin Elmer Lambda 25 UV-visible spectrophotometer, and scanning was done from $1100 \mathrm{~nm}$ to $200 \mathrm{~nm}$. The bright-field TEM images were taken using a JEOL $200 \mathrm{keV}$ TEM. The samples for TEM were prepared by dropping a dispersion of the particles on copper grid supported Formvar films. Microtome was done on selected samples as described. X-ray powder diffractograms (XRD) were measured with a Shimadzu diffractometer with $\mathrm{Cu} \mathrm{K} \alpha$ radiation.

\section{RESULTS}

\section{Nanoparticle characterization}

Fig. 1 shows the UV-visible spectrum of silver nanoparticles synthesized by chemical process. The spectrum shows the characteristic peak of silver nanoparticles at $415 \mathrm{~nm}$. 
Time bound characterization of silver ion solution taken from the cell well

The process of $\mathrm{Ag}^{2+}$ reduction on exposure to human cells can easily be tracked by monitoring of UV-visible spectroscopy measurements. We used the silver ions in hepes. This medium was found to be stable to the cells. Sodium nitrate was used to maintain ionic balance. Subsequently, $\mathrm{pH}$ was adjusted to 7.2 using sodium hydroxide. The UV-visible spectrum of the $\mathrm{Ag}^{2+}$ in HEPES is taken for 24 and 96 hrs which shows the absence of peak corresponding to silver nanoparticle (Fig. 2). The UV-visible spectrum of the $\mathrm{Ag}^{2+}$ sample after 24, 55, 72, and $96 \mathrm{hrs}$ of exposure to HEK-293, HeLa, and SiHa (Figs. 3-8) showed a well-defined surface plasmon band centered around 420-435 nm characteristic of colloidal silver. Further, the steady increase in the peak absorbance value for all experimental samples over a period of 96-hrs suggest that reduction process is slow and is a biological process. The solution at this stage becomes yellow in color. The cells due to over stressful condition detach itself from the well. The intracellular reduction of cell samples is also easily tracked by UV-visible spectroscopy measurements. The cells attached to the wells were detached by trypsinization and were subsequently lysed following experimental protocol for cell lysis. The UV-visible spectra of lysed samples were taken after $24,55,72$, and $96 \mathrm{hrs}$ of exposure to $\mathrm{Ag}^{2+}$ solution. The peak value is subsequently higher than the corresponding spectra got by extracellular reduction at different time intervals.

The fact that the presence of nanoparticles was showing up in the samples collected from the solution (external to the cell membrane) proves the presence of silver nanoparticles in the solution without any

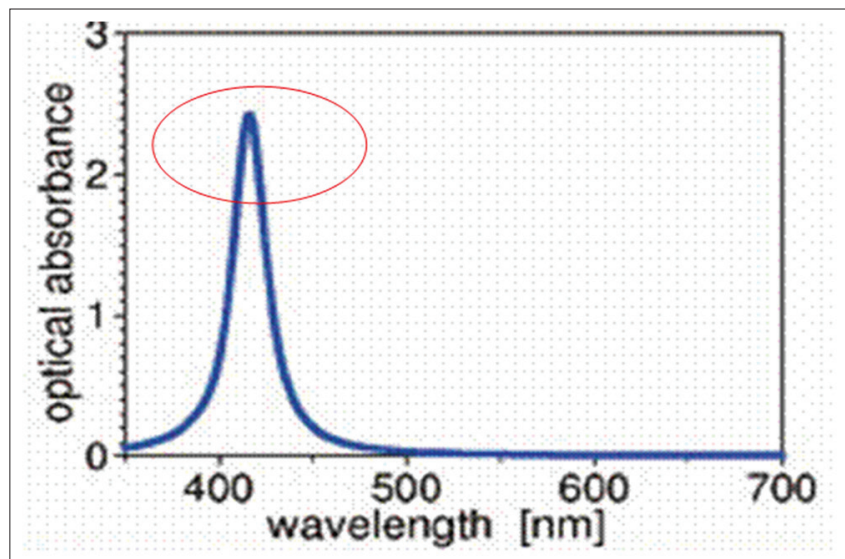

Fig. 1: Ultraviolet-visible spectrum of citrate capped silver nanoparticles

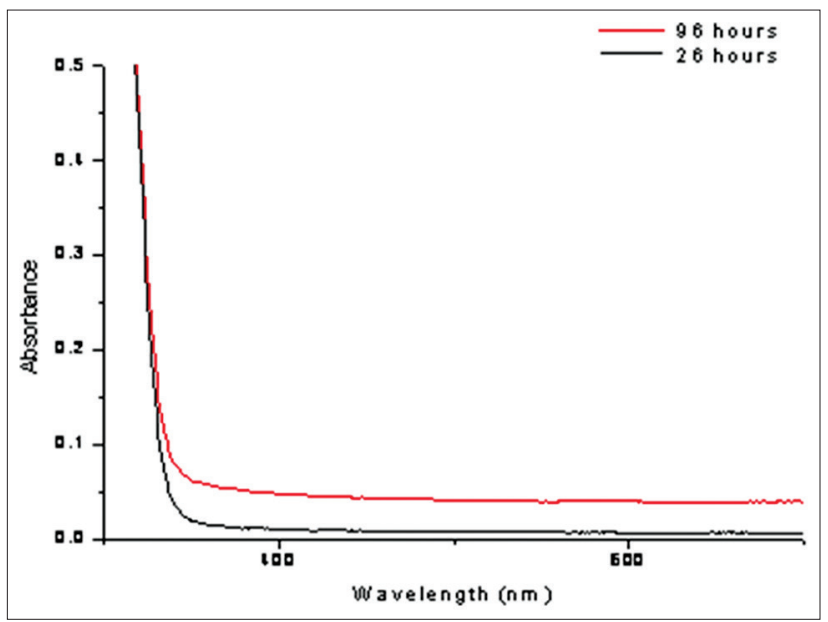

Fig. 2: Time bound ultraviolet-visible measurements for $0.001 \mathrm{M}$ silver ions in HEPES aggregation. In addition, the detached cells from the well after exposure to $\mathrm{Ag}^{2+}$ solution were intensely yellowish brown in color at all-time intervals. Before detaching, the cells present in the well were found to be yellowish in color after 96 hrs (Figs. 9-14).

Fig. 15 shows the XRD patterns for HEK samples obtained after lysing the cells and plating the lysate on a glass slide. It clearly shows the

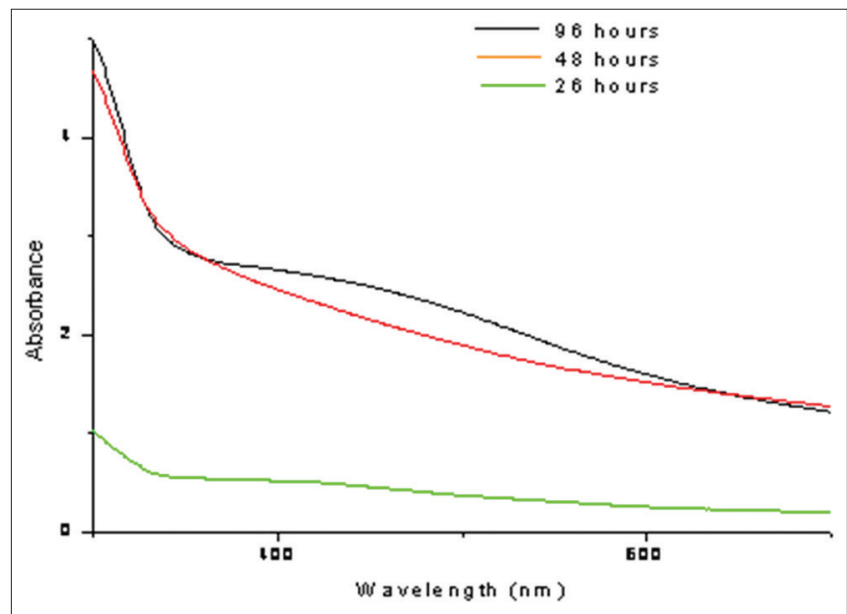

Fig. 3: Time bound ultraviolet-visible measurements for human embryonic kidney cells with $0.001 \mathrm{M}$ silver ions in HEPES

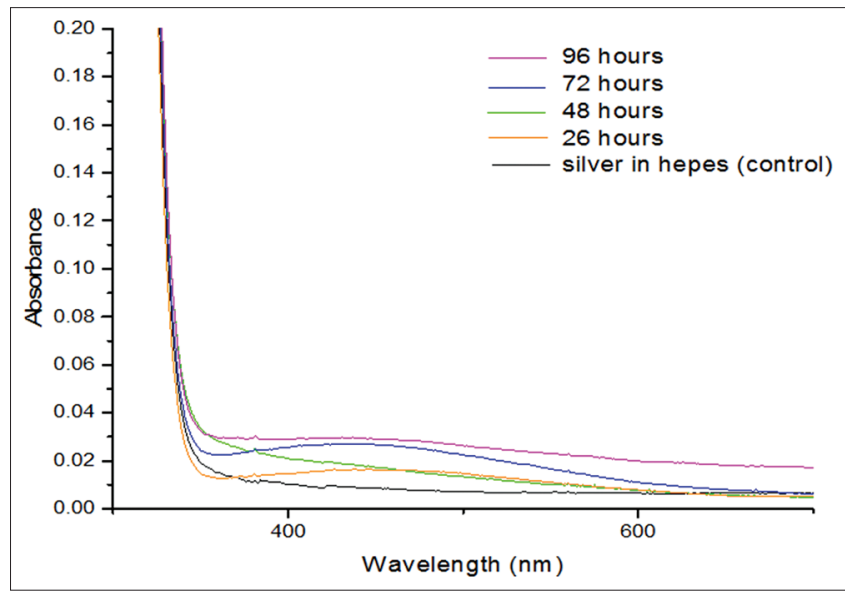

Fig. 4: Time bound ultraviolet-visible measurements for HeLa cells with $0.001 \mathrm{M}$ silver ions in HEPES

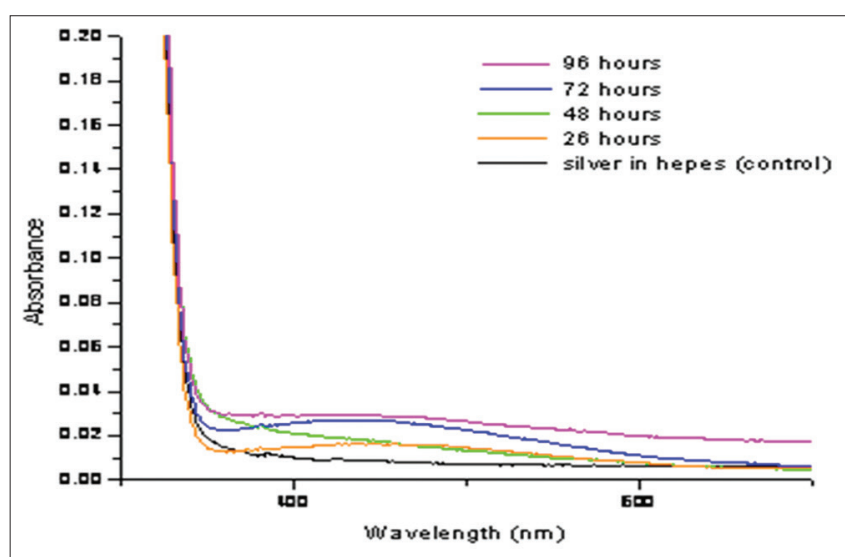

Fig. 5: Time bound ultraviolet-visible measurements for $\mathrm{SiHa}$ cells with $0.001 \mathrm{M}$ silver ions in HEPES 


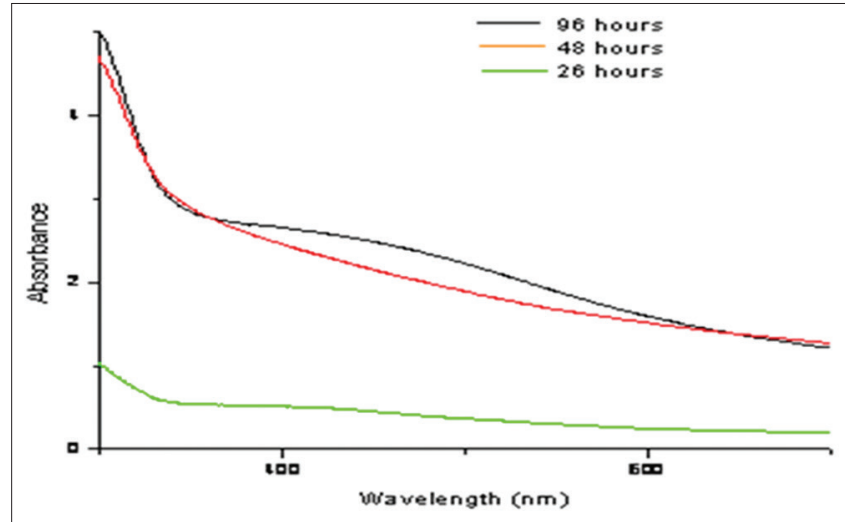

Fig. 6: Time bound ultraviolet-visible measurements for lysed human embryonic kidney cells treated with $0.001 \mathrm{M}$ silver ions in HEPES

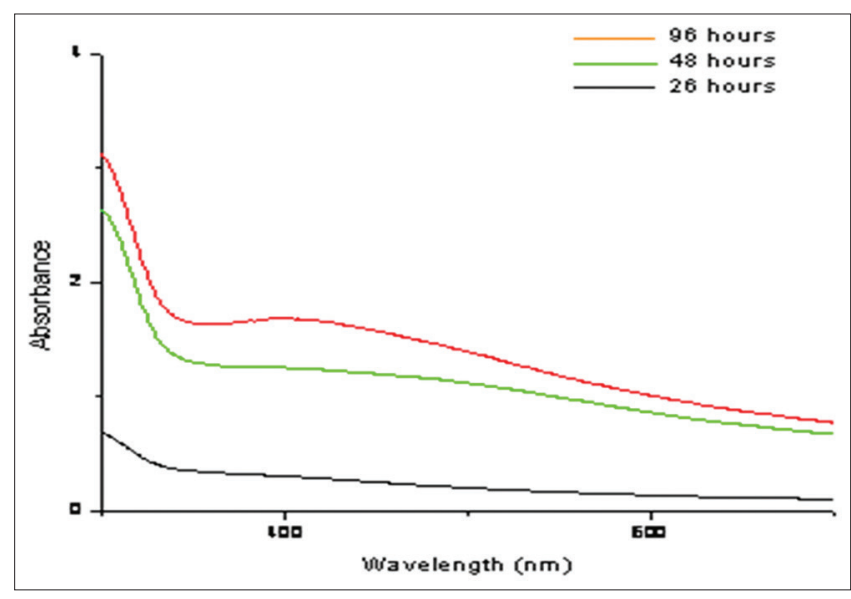

Fig. 7: Time bound ultraviolet-visible measurements for lysed HeLa cells treated with $0.001 \mathrm{M}$ silver ions in HEPES

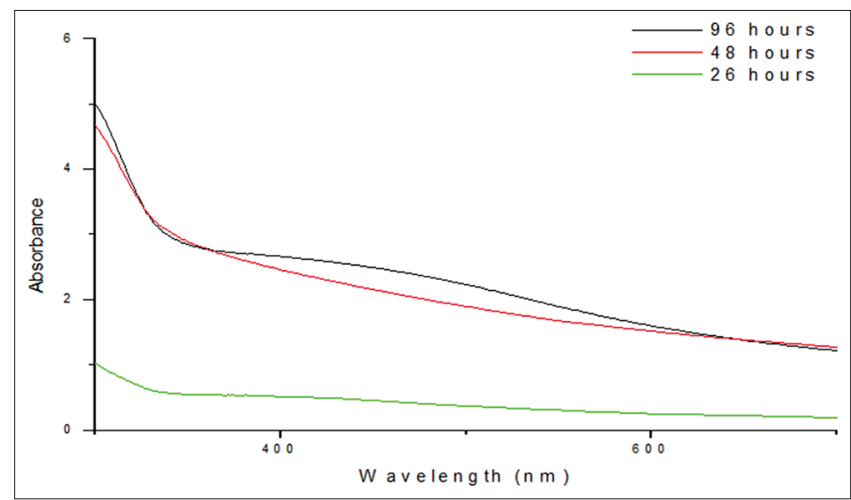

Fig. 8: Time bound ultraviolet-visible measurements for lysed SiHa cells treated with $0.001 \mathrm{M}$ silver ions in HEPES

appearance of three prominent peaks which are characteristic of crystal lattice of silver nanoparticles. Peak at 38 is due to rejection from (111), peak at 44 is due to reflection from (200), and peak at 65 is due to reflection from (220).

Electron diffraction patterns of ultramicrotomed samples show the presence of silver crystals (Fig. 16). It is also well known that various kinds of proteins present inside the cytoplasm of cell have amine and/or thiol groups present in them. The presence of these two groups crates favorable binding interactions between proteins and nanoparticles

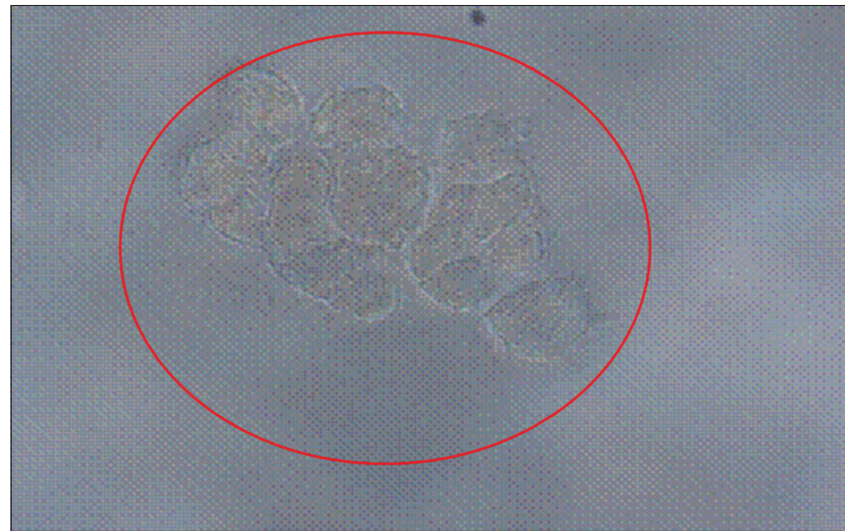

Fig. 9: Photograph of human embryonic kidney-293 cells with silver ions (Day $1, \times 40)$

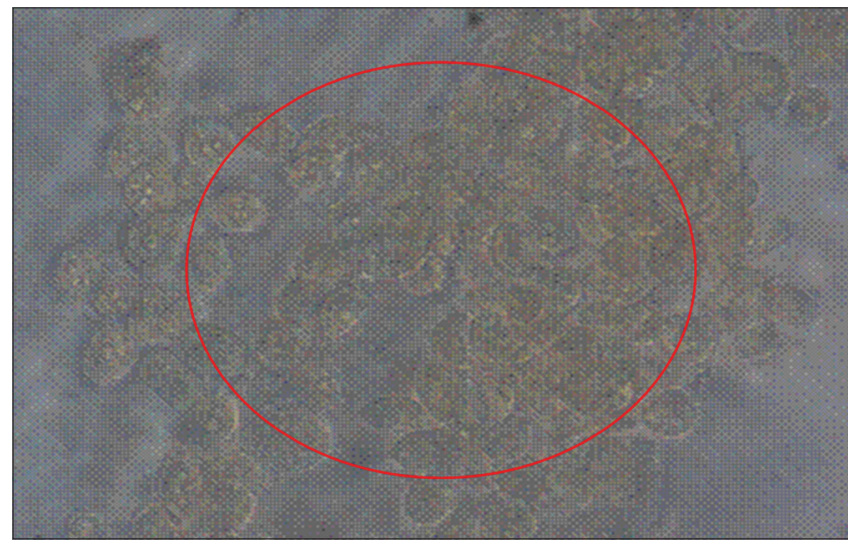

Fig. 10: Photograph of human embryonic kidney-293 cells with silver ions (Day 4, ×40)

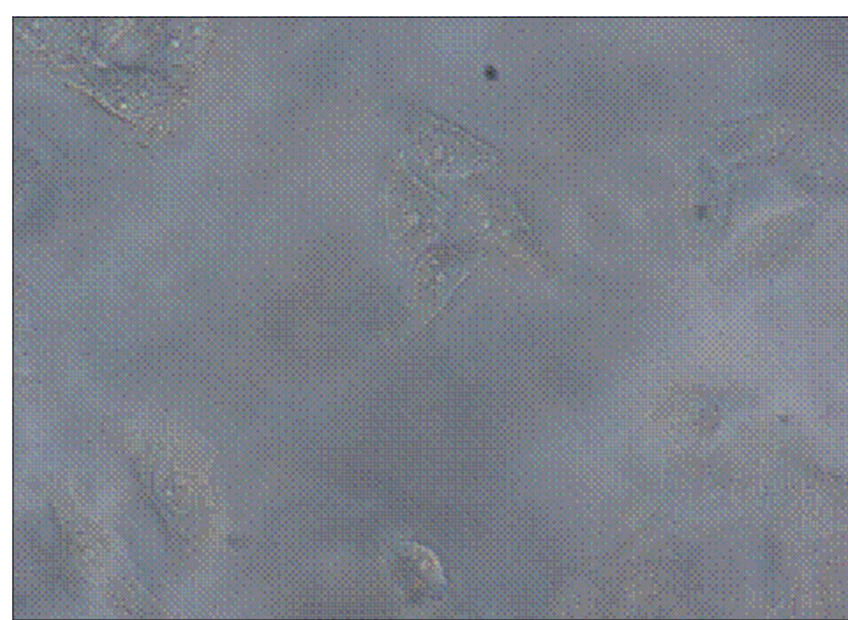

Fig. 11: Photograph of HeLa cells with silver ions (Day 1, ×40)

surfaces. The presence of capping agent, in addition to causing size changes, also contributes to stabilization of nanoparticles and shift in characteristic peak value position in UV-visible spectrometry measurements. The appearance of peak at above $420 \mathrm{~nm}$ suggests that silver nanoparticles are capped with certain molecular species containing amine group or cysteine residues in protein, etc.

As observed from the images, the cells had become hugely stressed out (Figs. 9-14), due to absence of growth medium and their involvement in reduction of silver ions. There was no further growth observed in 


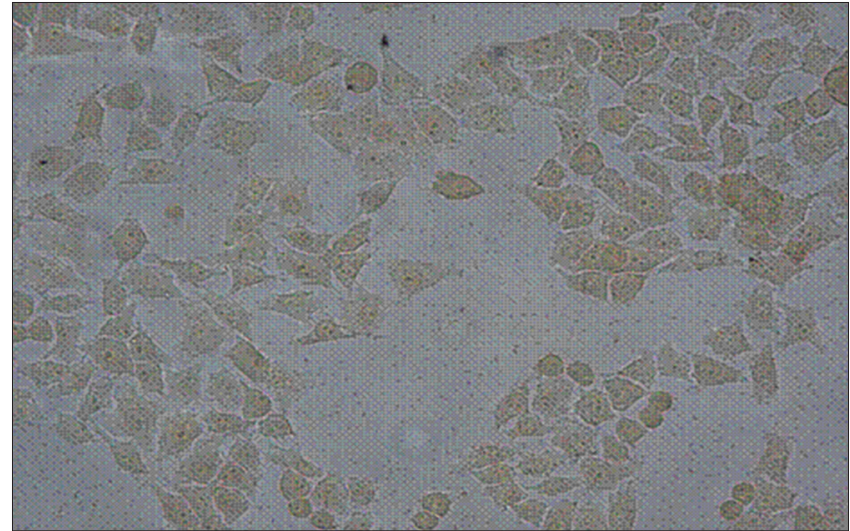

Fig. 12: Photograph of HeLa cells with silver ions (Day 4, ×40)

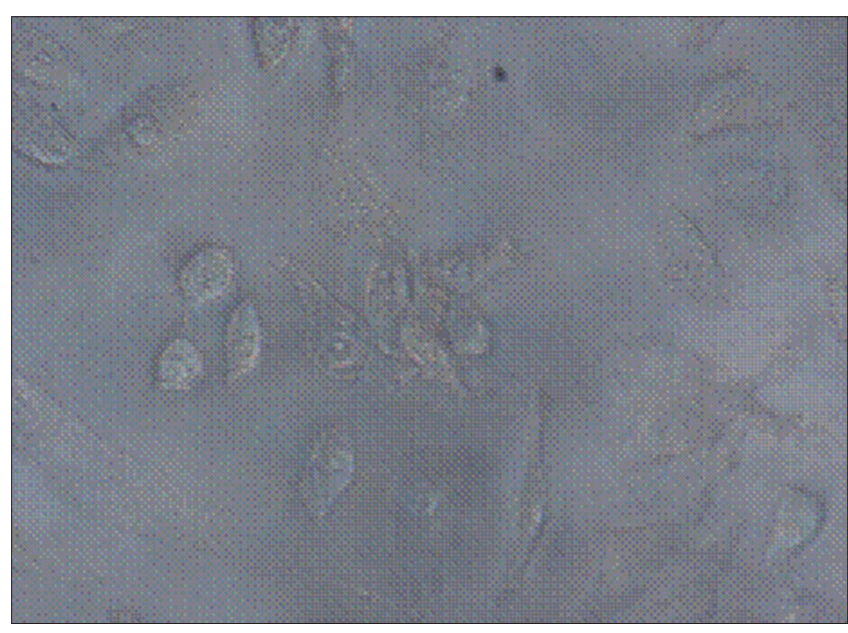

Fig. 13: Photograph of SiHa cells with silver ions (Day $1, \times 40$ )

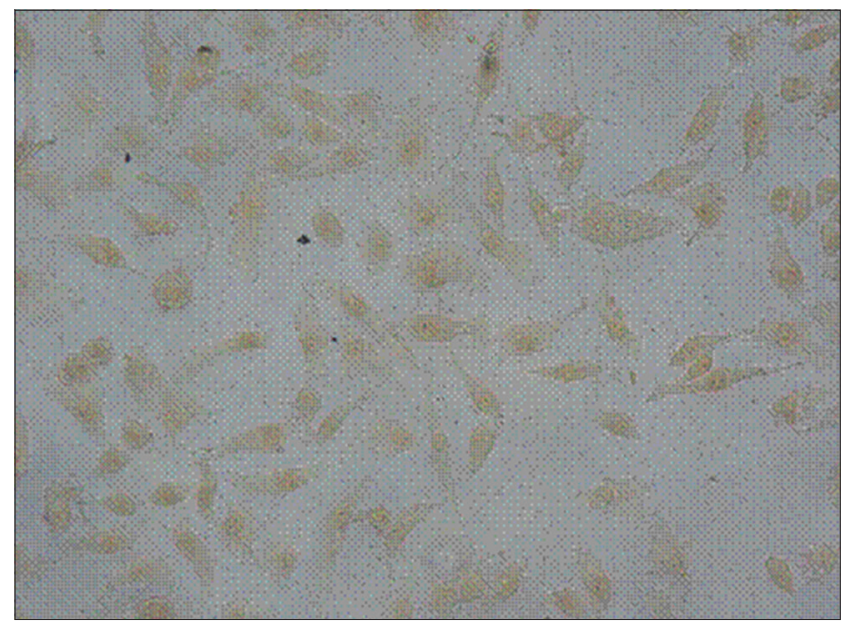

Fig. 14: Photograph of SiHa cells with silver ions (Day $4, \times 20$ )

the cells after day 0 as nutrient medium removed. The changes in cell morphology were observable. TEM images show the additional data of presence of silver nanoparticles in the cell lines (Figs. 17-20).

\section{DISCUSSION}

It is reported that silver nanoparticles have found to be useful in the field of biomolecular detection and diagnostic and therapeutic agents and antimicrobials for drug delivery and targeting. Various strategies are involved in the preparation of silver nanoparticles by physical and

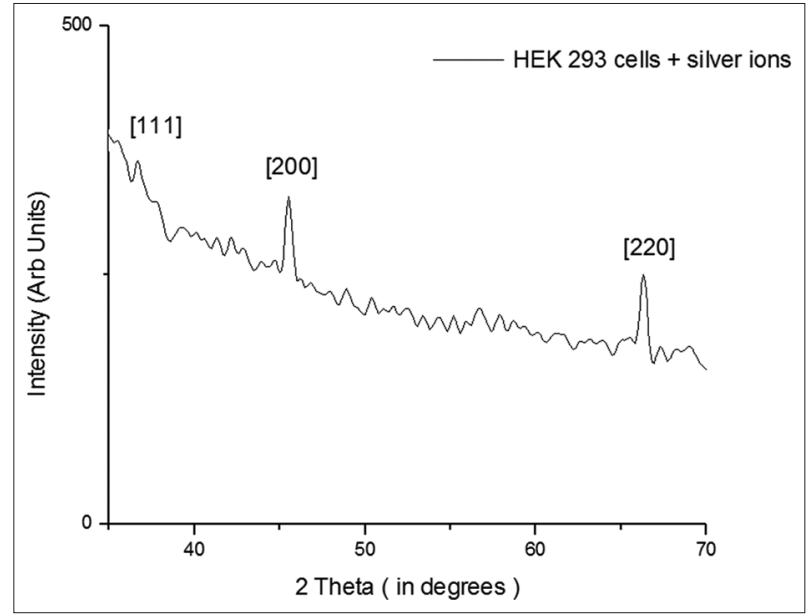

Fig. 15: X-ray diffractogram of human embryonic kidney-293 cells after treatment with silver ion solution (lysed)

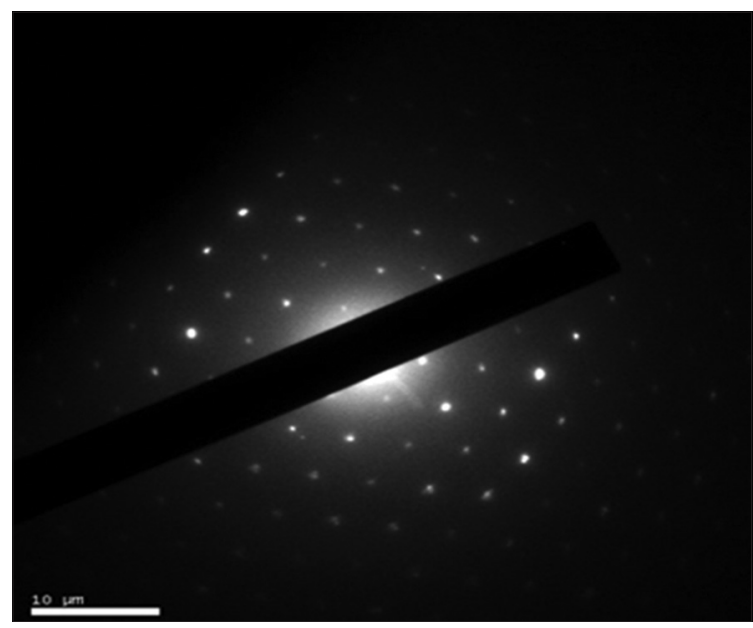

Fig. 16: Electron diffraction of human embryonic kidney-293 cells after treatment with silver ion solution (lysed)

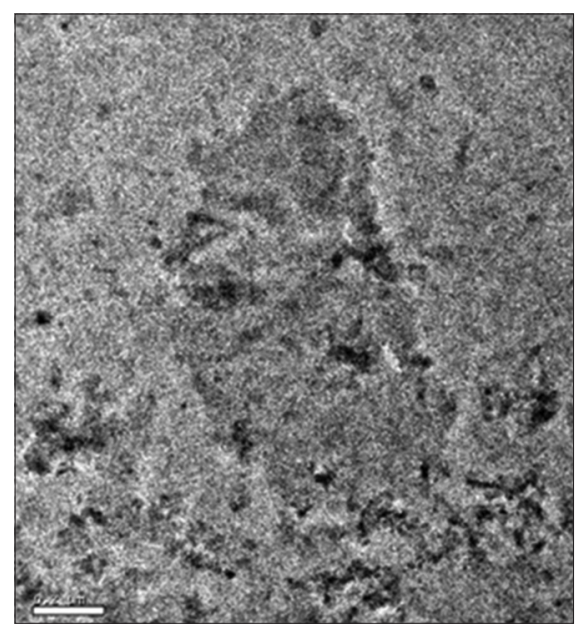

Fig. 17: Transmission electron microscopy image of HeLa cell line treated with silver ions for $96 \mathrm{hrs}$

chemical methods which are useful to produce nanoparticles with low yield and environmental issues such as usage of volatile solvents and high-temperature processes such as pyrolysis and high-attrition process. Biological process for preparation of silver nanoparticle is 


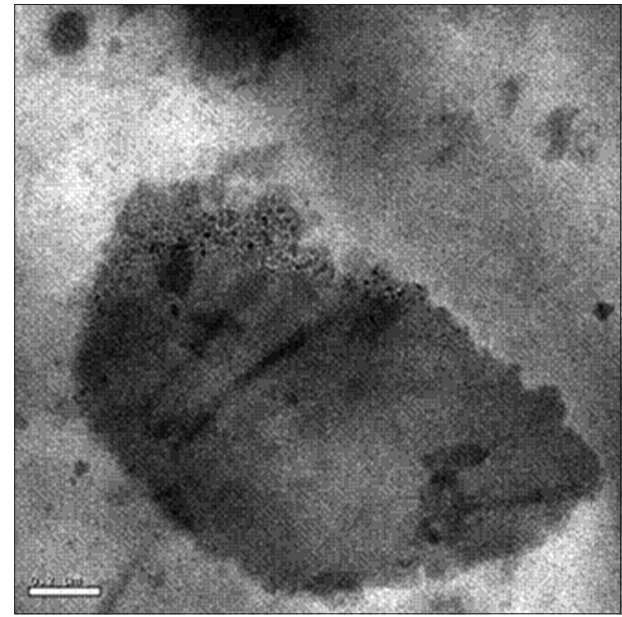

Fig. 18: Transmission electron microscopy image of HeLa cell line treated with silver ions for $96 \mathrm{hrs}$

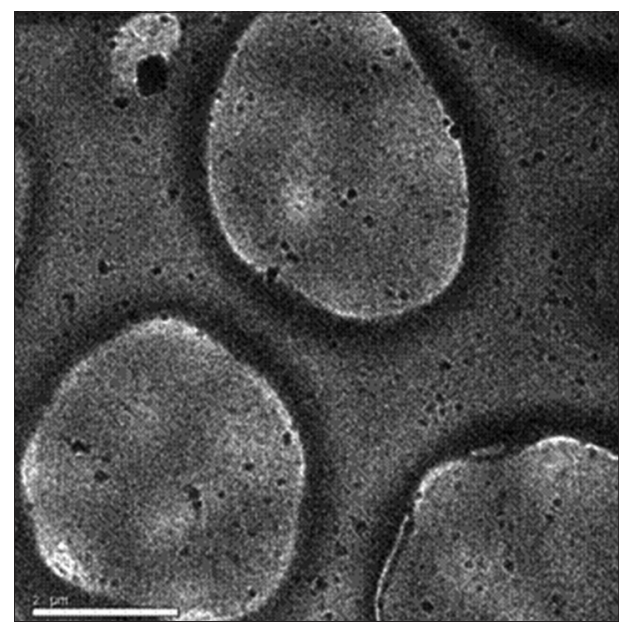

Fig. 19: Transmission electron microscopy image of human embryonic kidney cell line treated with silver ions for $96 \mathrm{hrs}$

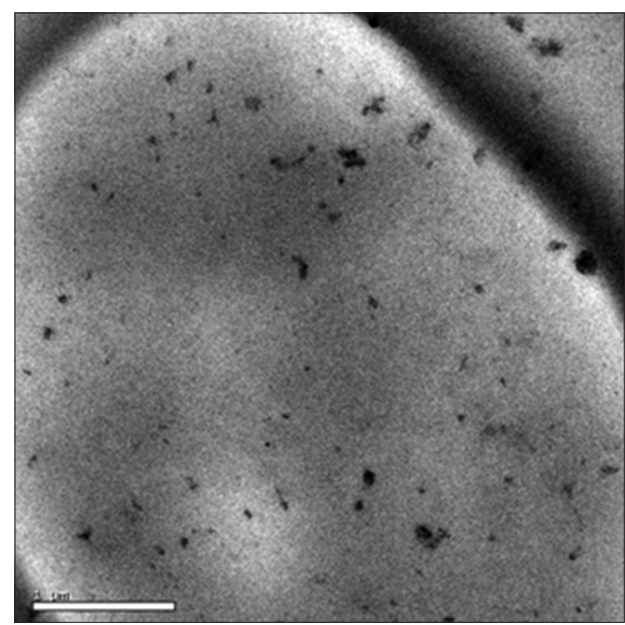

Fig. 20: Transmission electron microscopy image of human embryonic kidney cell line treated with silver ions for $96 \mathrm{hrs}$

an alternative to replace conventional method and it will be expected that the biological process could produce clean and high yield of silver nanoparticles. Biosynthesis approach utilizing living cells for production of silver nanoparticles has emerged as a simple, clean, and viable alternative for conventional processes. It is testified that a number of biological systems including microbial and plant cells are used for synthesis of nanoparticles [27].

The utilization of mammalian cells used for biosynthesis of silver nanoparticles is a novel approach in this work. The cancer and noncancerous cell lines are used for preparation of silver nanoparticles. The biosynthesized silver nanoparticles were characterized by optical absorption spectroscopy. When metal nanoparticles are exposed to electromagnetic waves, the oscillating electric field causes electron in the conduction band to oscillate. When the frequency of the oscillation of electrons becomes equal to the frequency of incident light, resonance takes place which results in the Plasmon absorption peak. This happens in the visible region of silver nanoparticles (Fig. 1).

The exact mechanism of silver ion reduction, transport into cells, and its subsequent nucleation is yet to be studied thoroughly. It is well known that sugars and enzymes present on the cell wall and within cytoplasm can accomplish the reduction process. The secreted proteins from the cells to the silver solution medium might also assist in the reduction process. Although the cells become dead, the subsequent increase in the Plasmon peaks of lysed samples at increasing time intervals suggests the cell membrane becoming porous. The transport of silver ions inside the cells may be facilitated by silver ions acting as biomimetic for transport through ionic channels. Furthermore, electrostatic interactions are created between membrane and cations due to negatively charged nature of membrane surface. This interaction may favorably increase the rate of ion transport inside the cells. Based on this investigation, we show that both intra- and extra-cellular synthesis of silver nanoparticles observed in all the three cell lines.

\section{CONCLUSION}

The synthesis of silver nanoparticles might be due to reduction process by the proteins or carbohydrate groups in the cell. The silver nanoparticles might be capped by the biomolecules stabilizing the nanoparticle. Several other studies are in progress to find the location inside the cell where the synthesis is occurring and to characterize the intra- and extra-cellular silver nanoparticles. This method could be novel process of synthesis of silver nanoparticles using cell culture and will be applicable in the area of drug targeting and delivery to the cancer cell [28].

\section{REFERENCES}

1. Nam JM, Thaxton CS, Mirkin CA. Nanoparticle - Based biobar codes for the ultrasensitive detection of proteins. Science 2003;301(5641):1884-6.

2. Tkachenko AG, Xie H, Coleman D, Glomm W, Ryan J, Anderson MF et al. Multifunctional gold nanoparticle-peptide complexes for nuclear targeting. J Am Chem Soc 2003;125(16):4700-1.

3. Hirsch LR, Stafford RJ, Bankson JA, Sershen SR, Rivera B, Price RE et al. Nanoshell-mediated near-infrared thermal therapy of tumors under magnetic resonance guidance. Proc Natl Acad Sci U S A 2003;100:13549-54

4. Blakemore RP. Magnetotactic bacteria. Annu Rev Microbiol 1982;36:217-38.

5. Dameron CT, Reese RN, Mehra RK, Kortan AR, Caroll PJ, Steigerwald LE, et al. Biosynthesis of cadmium sulphide quantum semiconductor crystallites. Nature 1989;338:596-7.

6. Pooley FD. Bacteria accumulate silver during leaching of sulphide ore minerals. Nature 1982;296:642-3.

7. Labrenz M, Druschel GK, Thomsen-Ebert T, Gilbert B, Welch SA, Kemner KM, et al. Formation of sphalerite ( $\mathrm{ZnS}$ ) deposits in natural biofilms of sulfate-reducing bacteria. Science 2000;290:1744-7.

8. Klaus T, Joerger R, Olsson E, Granqvist CG. Silver-based crystalline nanoparticles, microbially fabricated. Proc Natl Acad Sci U S A 1999;96(24):13611-4

9. Klaus-Joerger T, Joerger R, Olsson E, Granqvist C. Bacteria as workers in the living factory: Metal-accumulating bacteria and their potential for materials science. Trends Biotechnol 2001;19(1):15-20.

10. Wong KK, Mann S. Biomimetic synthesis of cadmium sulphide-ferritin 
nanocomposites. Adv Mater 1996;8:928-31.

11. Liz-Marzan LM. Nano - Metals: Formation and color. Mater Today 2004; 7:26-31

12. Mulvaney P. Surface plasmon spectroscopy of nanosized metal particles. Langmuir 1996;12:788-800.

13. Burda C, Chen X, Narayanan R, El-Sayed MA. Chemistry and properties of nanocrystals of different shapes. Chem Rev 2005;105(4):1025-102.

14. Schultz S, Smith DR, Mock JJ, Schultz DA. Single-target molecule detection with nonbleaching multicolor optical immunolabels. Proc Natl Acad Sci U S A 2000;97(3):996-1001.

15. Liau SY, Read DC, Pugh WJ, Furr JR, Russell AD. Interaction of silver nitrate with readily identifiable groups: Relationship to the antibacterial action of silver ions. Lett Appl Microbiol 1997;25(4):279-83.

16. Gupta A, Silver S. Silver as a biocide: Will resistance become a problem? Nat Biotechnol 1998;16(10):888.

17. Nomiya K, Yoshizawa A, Tsukagoshi K, Kasuga NC, Hirakawa S, Watanabe J. Synthesis and structural characterization of silver(I), aluminium(III) and cobalt(II) complexes with 4-isopropyltropolone (hinokitiol) showing noteworthy biological activities. Action of silver(I)-oxygen bonding complexes on the antimicrobial activities. J Inorg Biochem 2004;98:46-60.

18. Sondi I, Salopek-Sondi B. Silver nanoparticles as antimicrobial agent: A case study on E. coli as a model for Gram-negative bacteria. J Colloid Interface Sci 2004;275(1):177-82.
19. Elechiguerra JL, Burt JL, Morones JR, Camacho-Bragado A, Gao X, Lara $\mathrm{HH}$, et al. Interaction of silver nanoparticles with HIV-1. J Nanobiotechnology 2005;3:6.

20. Shankar SS, Ahmad A, Sastry M. Geranium leaf assisted biosynthesis of silver nanoparticles. Biotechnol Prog 2003;19(6):1627-31.

21. Rosemary MJ, Pradeep T. Solvothermal synthesis of silver nanoparticles from thiolates. J Colloid Interface Sci 2003;268:81-4.

22. Xie Y, Ye R, Liu H. Synthesis of silver nanoparticles in reverse micelles stabilized by natural bio surfactant. Colloids Surf A 2006;279:175-8.

23. Bhainsa KC, D'Souza SF. Extracellular biosynthesis of silver nanoparticles using the fungus Aspergillus fumigatus. Colloids Surf B Biointerfaces 2006;47(2):160-4.

24. Kowshik M, Ashtaputre S, Kharrazi S, Vogel W, Urban J, Kulkarni SK, et al. Extracellular synthesis of silver nanoparticles by a silver-tolerant yeast strain MKY3. Nanotechnology 2003;14:95-100.

25. Zhang Y, Chen F, Zhuang J, Tang Y, Wang D, Wang Y, et al. Synthesis of silver nanoparticles via electrochemical reduction on compact zeolite film modified electrodes. Chem Commun (Camb) 2002:2814-5.

26. Hayat MA. Colloidal Gold: Principles, Methods, and Applications. New York: Academic Press, Inc.; 1989.

27. Mandal S, Phadtare S, Sastry M. Interfacing biology with nanoparticles. Curr Appl Phys 2005;5:127-218.

28. Prasanna S. Extracellular and Intracellular Synthesis of Silver Nanoparticles, M.Tech Thesis, Anna University; 2006. 